\title{
Kinetic studies and optimization of heterogeneous catalytic oxidation processes for the green biorefinery of wood
}

\author{
Boris N. Kuznetsov*1,2, Irina G. Sudakova ${ }^{1}$, Natalya V. Garyntseva ${ }^{1}$, Valery E. Tarabanko ${ }^{1}$, \\ Nikolay V. Chesnokov ${ }^{1}$, Laurent Djakovitch ${ }^{3}$, Franck Rataboul ${ }^{3}$ \\ 1 - Institute of Chemistry and Chemical Technology SB RAS, FRC KSC SB RAS, Krasnoyarsk, Russia \\ 2 - Siberian Federal University, Krasnoyarsk, Russia \\ 3 - IRCELYON, Lyon, F-69626 Villeurbanne Cedex, France \\ *E-mail: bnk@icct.ru; inm@icct.ru
}

\begin{abstract}
In the present work, a kinetic study and optimization of the process of spruce wood peroxide oxidation in "acetic acid-water" medium in the presence of suspended $\mathrm{TiO}_{2}$ catalyst at temperatures $70-100{ }^{\circ} \mathrm{C}$ were accomplished for the first time. The effect of wood species and organic solvent nature on the features of the processes of catalytic peroxide fractionation of wood biomass on microcrystalline cellulose and soluble organic products from lignin and hemicelluloses is described. Solid products of wood peroxide oxidation were characterized by FTIR, XRD, SEM, solid state ${ }^{13} \mathrm{C}$ CP-MAS NMR and soluble products were identified by GC-MS. The experimental optimization of the process of birch wood oxidation by oxygen in "water-alkaline" medium in the presence of suspended $\mathrm{Cu}(\mathrm{OH})_{2}$ catalyst was carried out at temperature range $160-180{ }^{\circ} \mathrm{C}$. The scheme of biorefinery of birch wood, based on catalytic oxidative fractionation of wood biomass with the production of pentosans, vanillin, syringaldehyde and levulinic acid was developed. The resulting products are in demand in many areas, including food, pharmaceutical, chemical, cosmetic industries, synthesis of new functional and biodegradable polymers.
\end{abstract}

Keywords wood, oxidation, solid catalysts, biorefinery

\section{Introduction}

The significant resources of wood biomass can be used as a renewable feedstock for large scale production of valuable chemicals and biofuels [1,2].

The biomass of various tree species consists of cellulose, lignin, hemicelluloses, extracted substances and insignificant quantity of inorganic components [3]. Cellulose represents the linear polysaccharide constructed from chains of glucose, linked by $\beta-1,4$ bonds. Hemicelluloses are branched polysaccharides, generally constructed from pentoses and hexoses connected by chains that are shorter than in cellulose. The lignin is an aromatic polymer with branched structure. Lignin macromolecules consist of substituted phenylpropane units, connected with each other by ether and carbon-carbon bridges [3].

The vegetable polymers are structured by complex way in plant cells and therefore are quite stable against chemical reagents and enzymes. In this regard, in traditional processes of lignocellulose biomass conversion the chemically aggressive and ecologically dangerous reagents, increased temperatures and pressures 
are applied [4]. Therefore, the traditional technologies of cellulose production and hydrolysis have low productivity, produce only limited range of products and negatively influence on an environment.

Current research trends in the development of new efficient processes of lignocellulosic biomass conversion into valuable chemicals, functional polymers and biofuels are associated with the use of solid catalysts and "green" reagents $[1,2,5,6]$.

Promising ways in the development of innovative technologies of wood complex processing into valuable products are connected with a design of integrated catalytic processes which ensure the total utilization of all main components of biomass [7-9]. Most of them include, as a key stage, biomass fractionation on polysaccharides and lignin. Their further conversions make it possible to produce various chemicals and liquid biofuels.

Reductive catalytic fractionation is the possible way to separate lignocellulosic biomass into ligninbased soluble mono-, di- and oligomers while retaining most of the carbohydrates in the pulp $[10,11]$.

Catalytic oxidation of lignins by molecular oxygen in water-alkaline medium allows to separate lignocellulosic biomass into aromatic aldehydes (mainly vanillin and syringaldehyde) and cellulose [12].

The processes of organosolv delignification in the presence of environmentally safe oxidants, like oxygen and hydrogen peroxide has drawn a lot of attention [13-15]. The new organosolv processes do not always allow obtaining high quality cellulose. However, they can be successfully used for the wood fractionation on cellulose and soluble lignin for the purpose of their further processing to chemicals and biofuels.

The processes of wood peroxide fractionation in "hydrogen peroxide-acetic acid-water" medium in the presence of $\mathrm{TiO}_{2}$ catalysts were employed for the green biorefinery of birch wood to xylose, pure cellulose, glucose and liquid hydrocarbons [16], larch wood to dihydroquercitin, arabinogalactan, microcrystalline cellulose and soluble low molecular weight lignin [17].

In the present work, a kinetic study and optimization of spruce wood peroxide fractionation in the medium of acetic acid - water over the catalyst $1 \% \mathrm{TiO}_{2}$ were carried out for the first time. The effect of wood and solvent nature on the features of catalytic peroxide oxidation of wood biomass was established.

The scheme of biorefinery of birch wood based on oxidative fractionation of wood biomass by oxygen on pentosans, vanillin, syringaldehyde and levulinic acid was developed.

\section{Experimental}

\subsection{Raw materials and chemical analysis}

Air dry sawdust (fraction 0.5-2.0 mm) of softwood (spruce, pine, abies, larch) and hardwood (aspen, birch) were used in experiments. The contents of main wood component were defined by analytical methods, common in wood chemistry [18]. The cellulose content in wood was defined by Kurschner method. The lignin content was determined by hydrolysis of the sample with $72 \mathrm{wt} \%$ of sulfuric acid at $20^{\circ} \mathrm{C}$ for $2.5 \mathrm{~h}$, followed by dilution of a solution with water and boiling for $1 \mathrm{~h}$. The hemicelluloses content was defined by McKein and Shoorly method using the hydrolysis by $2 \mathrm{wt} \% \mathrm{HCl}$ at $100{ }^{\circ} \mathrm{C}$ during $3 \mathrm{~h}$.

The composition of wood samples is given in Table 1 . 
Table 1 Composition of wood samples

\begin{tabular}{llcl}
\hline \multirow{2}{*}{ Wood } & \multicolumn{3}{c}{ Composition, wt \% } \\
\cline { 2 - 4 } & Cellulose & Hemicelluloses & Lignin \\
\hline Spruce wood & & & 28.1 \\
Pine wood & 47.3 & 16.7 & 26.6 \\
Abies wood & 45.2 & 17.9 & 28.1 \\
Larch wood & 41.8 & 26.8 & 21.7 \\
Aspen wood & 46.7 & 24.8 & 21.6 \\
Birch wood & 46.8 & 27.6 & \\
\hline
\end{tabular}

\subsection{Wood sawdust peroxide oxidation}

The process of wood sawdust peroxide oxidation is described in [17]. Wood sawdust (10 g) was charged into the $250 \mathrm{ml}$ glass reactor, and then a solution containing a mixture of acetic acid, hydrogen peroxide, deionized water and catalyst was added. The reaction mixture was stirred intensively $(700 \mathrm{rpm})$ at the selected temperature $(70$ $100{ }^{\circ} \mathrm{C}$ ) for $1-4 \mathrm{~h}$. The composition of the reaction solution varied within the following limits: hydrogen peroxide 4-6 wt \%, acetic acid 15-30wt\%, liquid/wood ratio (LWR) 10-20. The content of the catalyst $\mathrm{TiO}_{2}$ was $1 \%$ relative to the weight of the reaction mixture. At the end of the process, the solid precipitate was separated by vacuum filtration on a Buchner funnel, washed with deionized water, and dried at $105{ }^{\circ} \mathrm{C}$ to a constant weight. The yield of the cellulose product was determined by the weight method. The contents of cellulose, residual lignin and hemicelluloses in solid products were determined using the standard chemical methods [18].

The suspension of commercial $\mathrm{TiO}_{2}($ GOST 9808-84) with the average particle size of $10 \mu \mathrm{m}$, phase composition of $92 \%$ rutile and $8 \%$ anatase, and BET specific area $3 \mathrm{~m}^{2} / \mathrm{g}$ was used as a catalyst.

\subsection{Wood sawdust oxidation by $\mathrm{O}_{2}$}

The process of wood sawdust oxidation by $\mathrm{O}_{2}$ is described in [12].Oxidation of the wood was performed in a stainless-steel, PTFE-sealed batch reactor of 11 capacity at $160-170{ }^{\circ} \mathrm{C}$ and at the oxygen pressure $0.2-0.3$ $\mathrm{MPa}$. Reaction mass stirring was carried out with a magnetic stirrer $\left(800-900 \mathrm{~min}^{-1}\right)$. A reaction mass was prepared by sequentially adding the desired amount of distilled water, wood, $\mathrm{NaOH}$ aqueous solution, and aqueous solution of the catalyst $\left(\mathrm{CuSO}_{4} \cdot 5 \mathrm{H}_{2} \mathrm{O}\right)$, all while stirring. The reactor was heated to the desired temperature at a rate of $3-8{ }^{\circ} \mathrm{C} / \mathrm{min}$. Upon attaining the desired temperature, oxygen was introduced into the reactor, and its desired partial pressure was manually maintained along the course of the reaction. After the certain reaction duration, the gas phase was throttled from reactor. Then the reactor was cooled and opened. The reaction mass was filtered. Resulting solid was treated by $32 \mathrm{wt} \%$ of $\mathrm{HCl}$ in order to dissolve the copper oxide. Vanillin and syringaldehyde were extracted by chloroform.

\subsection{Infrared spectroscopy analysis (FTIR)}

Infrared spectroscopy analysis (FTIR) was carried out in transmission mode. Samples of cellulose (4 mg for each) were prepared in pellets with matrix $\mathrm{KBr}$. The spectra were recorded with Bruker Tensor-27 in the range of 4000-400 $\mathrm{cm}^{-1}$. Spectral data were processed by the program OPUS/YR (version 2.2).

\subsection{X-ray diffraction analysis (XRD)}

X-ray diffraction analysis was carried out using PANalyticalX'Pert Pro (PANalytical, Netherlands) spectrometer with CuK $\alpha$ radiation $(\lambda=0.54 \mathrm{~nm})$. The analysis was performed in the angle range of $2 \theta=5^{\circ}-70^{\circ}$ with a step of 
$0.1^{\circ}$ on the powder sample in a $2.5-\mathrm{cm}$ diameter cuvette. The crystallinity index of the cellulose was calculated from the ratio of crystalline peak intensity to the total intensity after subtracting the background signal.

\subsection{Solid state ${ }^{13}$ C CP-MAS NMR spectroscopy}

Solid state ${ }^{13} \mathrm{C}$ CP-MAS NMR spectra were recorded with the use of Bruker Avance III spectrometer, operating at $150.9 \mathrm{MHz} 13 \mathrm{C}$ resonance frequency. Sample was packed in $3.2 \mathrm{~mm}$ rotors and spun at $7.5 \mathrm{kHz}$. The spectrum was acquired at $25{ }^{\circ} \mathrm{C}$. Acquisition parameters were set as follows: acquisition time $0.33 \mathrm{~ms}$, crosspolarization contact time $3 \mathrm{~ms}, 4096$ accumulated scans with repetition interval $5 \mathrm{~s}$. Chemical shifts were referenced relative to adamantane as external standard (methylene at $\delta^{13} \mathrm{C}=29.5 \mathrm{ppm}$ ). The acquired free induction decays were multiplied with exponential window function with $25 \mathrm{~Hz}$ line broadening before Fourier transformation.

\subsection{Scanning electron microscopy (SEM)}

Scanning electron microscopy of the samples was performed on a JSM7001 F (JEOL, Japan) microscope with acceleration potentional $15 \mathrm{kV}$. Samples were coated on carbon support.

\subsection{Gas Chromatography mass spectrometry (GC-MS)}

The liquid products of wood catalytic oxidation were analyzed by GC-MS using Agilent 7890A chromatograph fitted with an Agilent 7000A Triple Quad mass-selective detector (Agilent, United States) by recording the total ion current. The products were separated in an HP-5MS capillary column $(30 \mathrm{~m}$ in length, $0.25 \mathrm{~mm}$ in inner diameter) in the temperature programmed mode while raising the temperature from 40 to $250^{\circ} \mathrm{C}$ at a rate of $3^{\circ} \mathrm{C} / \mathrm{min}$

\subsection{Gel permeation chromatography}

Soluble lignin samples were examined using a gel permeation chromatograph ("Agilent Technologies@, 1260Infinity, U.S.) with a refractive index detector, using an Agilent PL gel Mixed-C column. Chloroform was used as the eluent, with a flow rate of $1.0 \mathrm{ml} / \mathrm{min}$ at $40{ }^{\circ} \mathrm{C}$. Narrow polydispersity polystyrene standards (Agilent, U.S.) were used to generate a universal calibration curve, from which molecular weights (weight average, $\mathrm{Mw}$, and number average, $\mathrm{Mn}$ ) and polydispersity were determined.

\section{Results and Discussion}

\subsection{Kinetic study and optimization of spruce wood peroxide oxidation over $\mathrm{TiO}_{2}$ catalyst}

In order to optimize the process of spruce wood peroxide oxidation over $\mathrm{TiO}_{2}$ catalyst in acetic acid water medium the effect of temperature, concentrations of hydrogen peroxide and acetic acid, liquid/wood ratio (LWR) and time on the dynamics of lignin removal from wood was studied.

The increase of temperature from $70{ }^{\circ} \mathrm{C}$ to $100{ }^{\circ} \mathrm{C}$ reduces significantly the content of residual lignin and of hemicelluloses in the cellulose product (Table 2). But at the same time the yield of cellulose product is decreased. Thus intensive oxidative depolymerization of lignin, hemicelluloses and the amorphous part of cellulose in wood takes place at temperature $100^{\circ} \mathrm{C}$. 
Table 2 Yield and composition of cellulose products obtained by spruce wood peroxide oxidation $\left(\mathrm{H}_{2} \mathrm{O}_{2} 6 \mathrm{wt}^{\%} \%\right.$, $\mathrm{CH}_{3} \mathrm{COOH} 30 \mathrm{wt} \%$, LWR 15, $1 \mathrm{wt} \% \mathrm{TiO}_{2}$ )

\begin{tabular}{|c|c|c|c|c|c|}
\hline \multirow{2}{*}{$\begin{array}{l}\text { Temperature, } \\
{ }^{\circ} \mathrm{C}\end{array}$} & \multirow[b]{2}{*}{ Time, $\mathrm{h}$} & \multirow{2}{*}{$\begin{array}{l}\text { Yield of cellulose } \\
\text { product, wt } \% *\end{array}$} & \multicolumn{3}{|c|}{ Composition of product, $\mathrm{wt} \% * *$} \\
\hline & & & Cellulose & Lignin & Hemicelluloses \\
\hline \multirow{4}{*}{70} & 1 & 69.3 & 64.0 & 27.3 & 8.1 \\
\hline & 2 & 68.6 & 64.7 & 26.8 & 7.9 \\
\hline & 3 & 65.6 & 67.7 & 24.1 & 7.6 \\
\hline & 4 & 68.0 & 69.3 & 22.5 & 7.6 \\
\hline \multirow{4}{*}{80} & 1 & 67.1 & 66.2 & 25.4 & 7.8 \\
\hline & 2 & 64.8 & 68.7 & 23.2 & 7.5 \\
\hline & 3 & 65.6 & 70.7 & 21.4 & 7.3 \\
\hline & 4 & 62.8 & 72.7 & 18.8 & 7.9 \\
\hline \multirow{4}{*}{90} & 1 & 63.7 & 69.7 & 22.0 & 7.7 \\
\hline & 2 & 63.4 & 72.3 & 19.7 & 7.4 \\
\hline & 3 & 57.8 & 78.8 & 14.1 & 6.5 \\
\hline & 4 & 54.6 & 81.3 & 11.6 & 6.5 \\
\hline \multirow{4}{*}{100} & 1 & 56.9 & 77.9 & 14.7 & 6.8 \\
\hline & 2 & 53.5 & 83.0 & 10.9 & 5.5 \\
\hline & 3 & 49.1 & 90.4 & 3.1 & 5.9 \\
\hline & 4 & 47.1 & 93.1 & 1.0 & 5.3 \\
\hline
\end{tabular}

* on abs.dry wood, ** on abs.dry product

Peroxide delignification of spruce wood at $70{ }^{\circ} \mathrm{C}$ during $4 \mathrm{~h}$ produces (with the yield of $68.0 \mathrm{wt} \%$ ) the cellulose product containing $69.3 \mathrm{wt} \%$ of cellulose and $7.6 \mathrm{wt} \%$ of lignin. The increase a temperature to $100{ }^{\circ} \mathrm{C}$ reduces the yield of cellulose product to $47.1 \mathrm{wt} \%$. The maximum content of cellulose in the product (93.1 wt $\%)$ was observed in the process of spruce wood delignification at $100{ }^{\circ} \mathrm{C}$ during 4 hours. The residual lignin and hemicelluloses contents in this product were reduced to $1.0 \mathrm{wt} \%$ and $5.3 \mathrm{wt} \%$ respectively.

The effect of $\mathrm{H}_{2} \mathrm{O}_{2}$ concentration on the yield and composition of cellulose products obtained at $100{ }^{\circ} \mathrm{C}$ was studied (Fig.1). In the presence of $2.0 \mathrm{wt} \%$ of $\mathrm{H}_{2} \mathrm{O}_{2}$ the yield of cellulose product is $60.5 \mathrm{wt} \%$, but this product has a rather high content of residual lignin (18.4 wt \%). When the concentration of $\mathrm{H}_{2} \mathrm{O}_{2}$ increases to 6.0 $\mathrm{wt} \%$, the content of residual lignin reduces to $1.0 \mathrm{wt} \%$. At the same time the yield of cellulose product decreased to $47.1 \mathrm{wt} \%$ as a result of deep oxidation of lignin and some part of wood polysaccharides.

According to the data obtained, the optimal concentration of $\mathrm{H}_{2} \mathrm{O}_{2}$, corresponding to a high yield of cellulose product (near $47 \mathrm{wt} \%$ on a.d.w.) with a low lignin content (1.0 wt $\%$ ) is $6 \mathrm{wt} \%$ (Fig.1). 


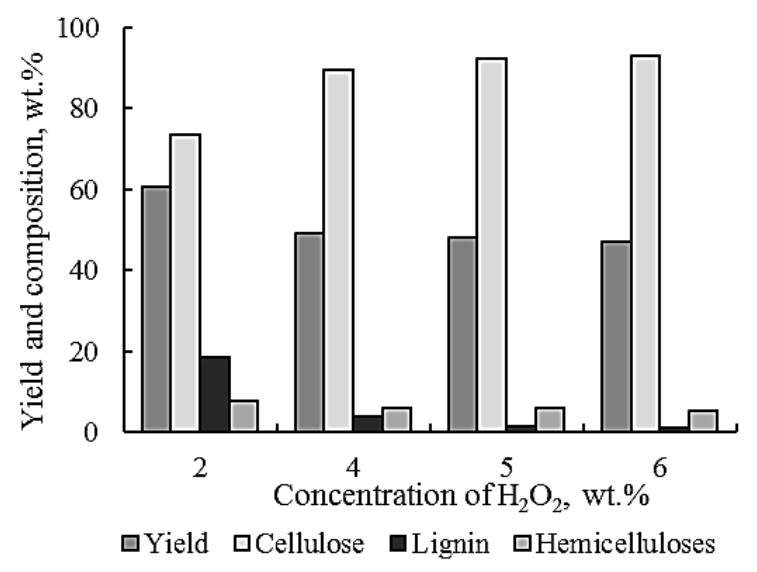

Fig.1 Influence of concentration of $\mathrm{H}_{2} \mathrm{O}_{2}$ on the yield and composition of cellulose products obtained from spruce wood $\left(100^{\circ} \mathrm{C}, \mathrm{CH}_{3} \mathrm{COOH} 30 \mathrm{wt} \%\right.$, LWR 15 , time $\left.4 \mathrm{~h}, 1 \mathrm{wt} \% \mathrm{TiO}_{2}\right)$

The increase of acetic acid concentration in the reaction mixture from $15 \mathrm{wt} \%$ to $30 \mathrm{wt} \%$ reduces the yield of cellulose product from 51.1 to $47.8 \mathrm{wt} \%$ (Fig.2). Simultaneously, the content of cellulose in cellulosic product is increased from 86.9 up to $92.7 \mathrm{wt} \%$ and that of residual lignin is reduced from 3.4 to $1.0 \mathrm{wt} \%$. According to obtained data the optimum concentration of acetic acid is nearly $25 \mathrm{wt} \%$. This concentration allows to save the acceptable yield of cellulose product (47.8 wt \%) with high content of cellulose $(92.7 \mathrm{wt} \%)$ and low content of residual lignin (1.3 wt\%).

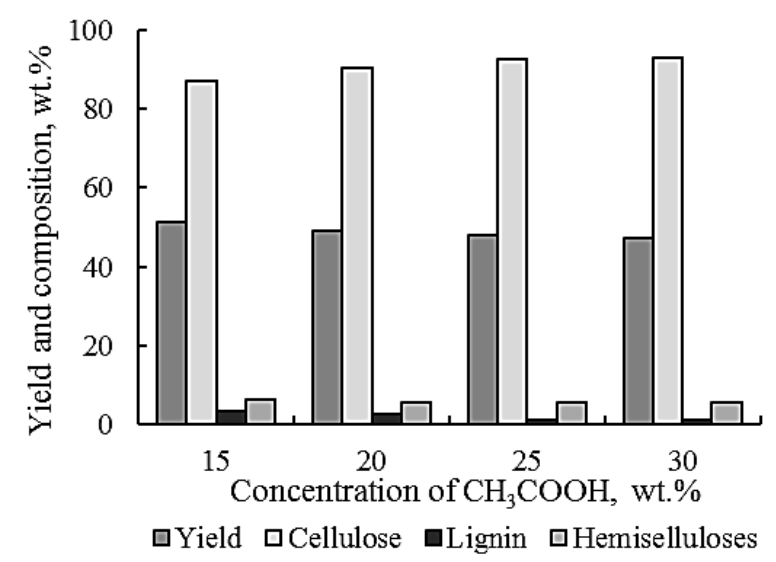

Fig.2 Influence of concentration of $\mathrm{CH}_{3} \mathrm{COOH}$ on the yield and composition of cellulose products obtained from spruce wood $\left(100{ }^{\circ} \mathrm{C}, \mathrm{H}_{2} \mathrm{O}_{2} 6 \mathrm{wt} \%\right.$, LWR 15 , time $\left.4 \mathrm{~h}, 1 \mathrm{wt} \% \mathrm{TiO}_{2}\right)$

The liquid/wood ratio (LWR) influences both on the yield and composition of cellulose products (Fig.3). The cellulose products obtained at LWR of 15-20 have low content of residual lignin (1.3-0.7 wt\%). The reduction of LWR to 10 increases both the yield of cellulose product (to $48.7 \mathrm{wt} \%$ ) and the residual lignin content (to $6.9 \mathrm{wt} \%$ ). A possible reason for this is a hindered diffusion of lignin oxidation products from wood to solution at low LWR. As a result, the reactive intermediates of lignin oxidative fragmentation are re-condensed to so-called "pseudo lignin"[19]. According to obtained data the optimal LWR for peroxide delignification of spruce wood at $100{ }^{\circ} \mathrm{C}$ is equal to 15 . 


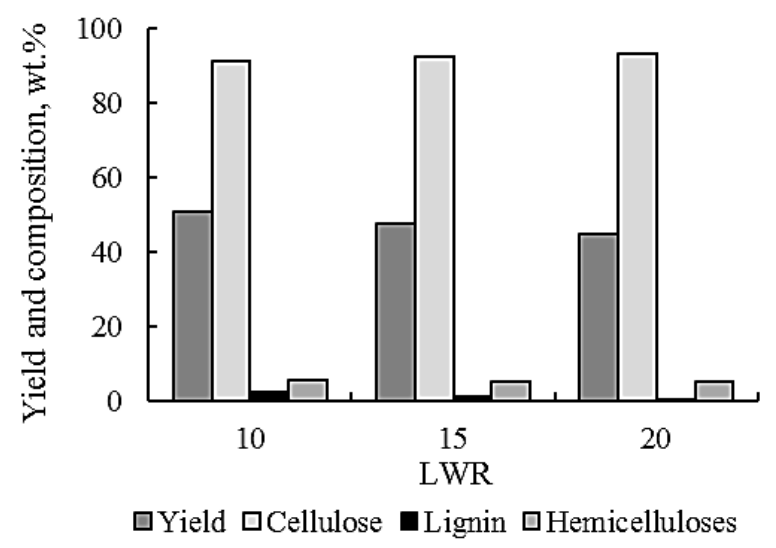

Fig.3 Influence of LWR on the yield and composition of cellulose products obtained from spruce wood $\left(100^{\circ} \mathrm{C}\right.$, $\mathrm{H}_{2} \mathrm{O}_{2} 6 \mathrm{wt} \%, \mathrm{CH}_{3} \mathrm{COOH} 25 \mathrm{wt} \%$, time $4 \mathrm{~h}, 1 \mathrm{wt} \% \mathrm{TiO}_{2}$ )

The kinetic study of spruce wood peroxide catalytic oxidation in the temperature range $70-100{ }^{\circ} \mathrm{C}$ was carried out. The variation of lignin concentration in the cellulose product was used for calculating the rate constants of delignification process. It was found that the process of lignin isolation from spruce wood is described by the first order equation (Fig.4).

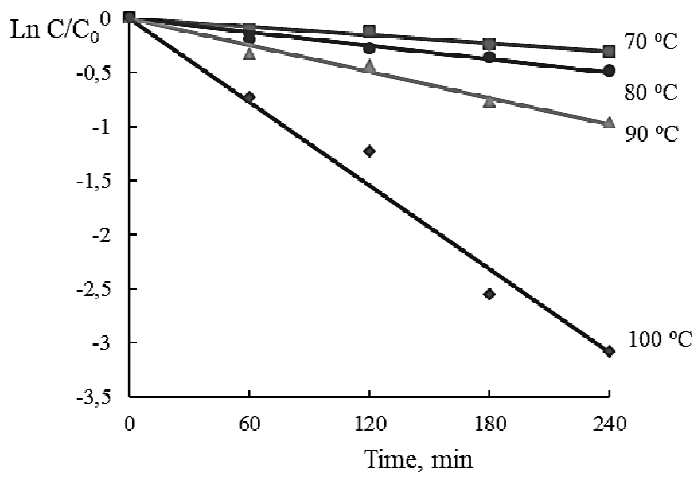

Fig.4 Time dependence of lignin concentration in cellulose products obtained by spruce wood peroxide oxidation $\left(\mathrm{H}_{2} \mathrm{O}_{2} 6\right.$ wt $\%, \mathrm{CH}_{3} \mathrm{COOH} 25 \mathrm{wt} \%$, LWR $\left.15,1 \mathrm{wt} \% \mathrm{TiO}_{2}\right)$

The rate constants of spruce wood peroxide fractionation process increase from $0.22 \cdot 10^{-4} \mathrm{~s}^{-1}$, to $2.1510^{-}$ ${ }^{4} \mathrm{~s}^{-1}$ with a rise in temperature from $70{ }^{\circ} \mathrm{C}$ to $100{ }^{\circ} \mathrm{C}$ (Table 3).

The activation energy of spruce wood peroxide fractionation process was determined using temperature dependence of the rate constants in Arrhenius coordinates. The rather high value of activation energy $(87 \mathrm{~kJ} / \mathrm{mol})$ points on the minor contribution of external diffusion limitations at the used conditions of spruce wood peroxide oxidation over $\mathrm{TiO}_{2}$ catalyst.

Table 3 Rate constants and activation energy of the process of spruce wood peroxide oxidation over $\mathrm{TiO}_{2}$ catalyst

\begin{tabular}{ccc}
\hline $\begin{array}{c}\text { Temperature, } \\
{ }^{\circ} \mathrm{C}\end{array}$ & $\begin{array}{c}\text { Rate constants } \\
\mathrm{k} \cdot 10^{-4}, \mathrm{~s}^{-1}\end{array}$ & Activation energy, $\mathrm{kJ} / \mathrm{mol}$ \\
\hline 70 & 0.22 & \\
80 & 0.35 & 87 \\
90 & 0.68 & \\
100 & 2.15 & \\
\hline
\end{tabular}


The numerical optimization of the process of spruce wood peroxide oxidation over $\mathrm{TiO}_{2}$ catalyst was carried out with the use of Statgraphics application software as in [17]. The purpose of the optimization was to determine the conditions for the effective removal of lignin from wood, while maintaining a sufficiently high yield of cellulose product.

As independent parameters, the following factors have been selected: $\mathrm{X}_{1}-\mathrm{H}_{2} \mathrm{O}_{2}$ concentration, wt $\% ; \mathrm{X}_{2}$ - liquid / wood ratio. The other process parameters were fixed: temperature $100{ }^{\circ} \mathrm{C}$, concentration of acetic acid $25 \mathrm{wt} \% ; \mathrm{TiO}_{2} 1 \mathrm{wt} \%$, time $4 \mathrm{~h}$.

The following output parameters for optimization were selected: $\mathrm{Y}_{1}$ - cellulose product yield, $\mathrm{wt} \% ; \mathrm{Y}_{2}$ -cellulose content in the product, $w \mathrm{t} \% ; \mathrm{Y}_{3}$ - lignin content in the product, $\mathrm{wt} \%$.

Optimization was performed with the use of generalized parameter of optimization $\left(\mathrm{W}_{\mathrm{a}}\right)$ which was calculated as in [17].

Analysis of variances showed that the effect of both factors $X_{1}$ and $X_{2}$ on the generalized parameter of optimizations is statistically significant (P-Value less than 0.05 and the confidence level above 97\%).

As a result of mathematical processing the following regression equation was obtained:

$$
\mathrm{Wa}=-0,9494+0,4827 \cdot \mathrm{X}_{1}+0,0466 \cdot \mathrm{X}_{2}-0,0416 \cdot \mathrm{X}_{1}{ }^{2}-0,0019 \cdot \mathrm{X}_{1} \cdot \mathrm{X}_{2}
$$

Response surface of the generalized parameter of the optimization is presented on Fig.5.

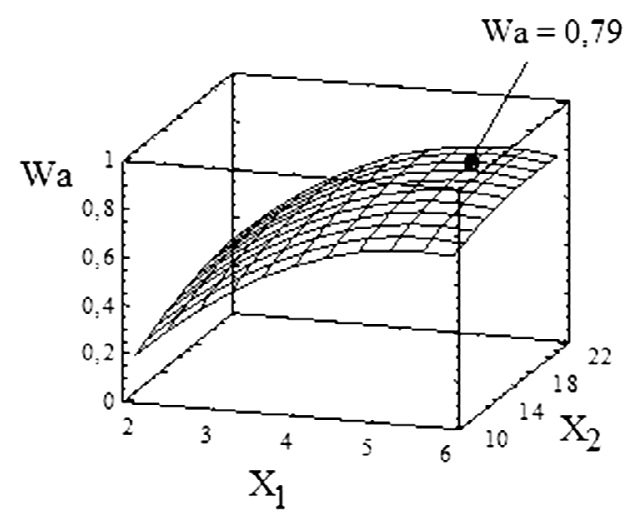

Fig.5 Response surface of the generalized parameter $\left(\mathrm{W}_{\mathrm{a}}\right)$ of the optimization of the process of spruce wood peroxide oxidation over $\mathrm{TiO}_{2}$ catalyst: $\mathrm{X}_{1}$ - initial concentration of $\mathrm{H}_{2} \mathrm{O}_{2}, \mathrm{X}_{2}$ - liquid /wood ratio

It was found, that the generalized parameter of the optimization is set to 0.79 . This corresponds to the following optimal conditions of spruce wood oxidation process: temperature $100{ }^{\circ} \mathrm{C}$, concentrations of $\mathrm{H}_{2} \mathrm{O}_{2} 6$ wt $\%$ and of $\mathrm{CH}_{3} \mathrm{COOH} 25 \mathrm{wt} \%$, LWR 15, duration $4 \mathrm{~h}$.

The cellulose obtained by catalytic peroxide oxidation of spruce wood at optimal conditions with an yield $47.8 \mathrm{wt} \%$ has the following composition ( $\mathrm{wt} \%$ ): cellulose 92.7, hemicelluloses 5.4, lignin 1.3.

According to the FTIR and XRD data, the structure of cellulose obtained at optimal conditions of spruce wood peroxide oxidation corresponds to that of commercial microcrystalline cellulose. Crystallinity index of cellulose from spruce wood, calculated from the ratio of height between the intensity of the crystalline peak and total intensity [20], is equal to 0.75 . The degree of polymerization is 650 .

According to SEM data, the samples of cellulose from spruce wood and industrial MCC Vivapur 101 consist of microfibrils with different length (Fig. 6). Some microfibrils are collected in bundles. 
A

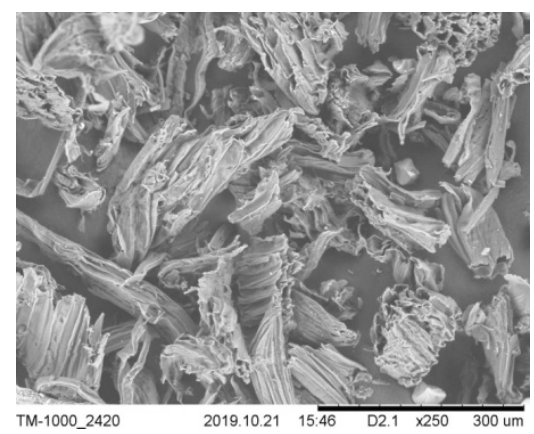

B

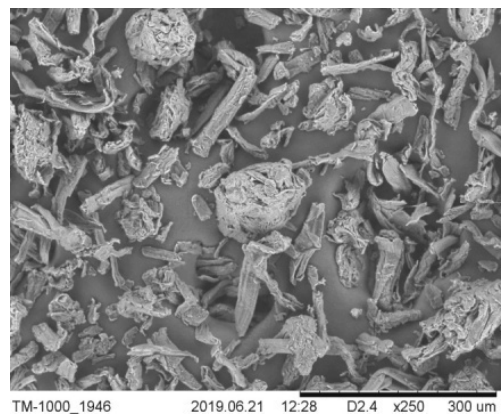

Fig.6 SEM images of cellulose obtained from spruce wood (A) and of industrial MCC Vivapur 101 (B)

In order to compare the structure of cellulose obtained from spruce wood and industrial MCC Vivapur, the ${ }^{13} \mathrm{C}$ CP-MAS NMR solid state analysis was performed. The resonance lines of cellulose from spruce wood and MCC Vivapur were almost similar (Fig. 7). Both spectra have resonance lines which indicate the presence of crystalline and amorphous forms of cellulose. Peaks have been assigned based on the literature data $[21,22]$ and are displayed in the Table 4.

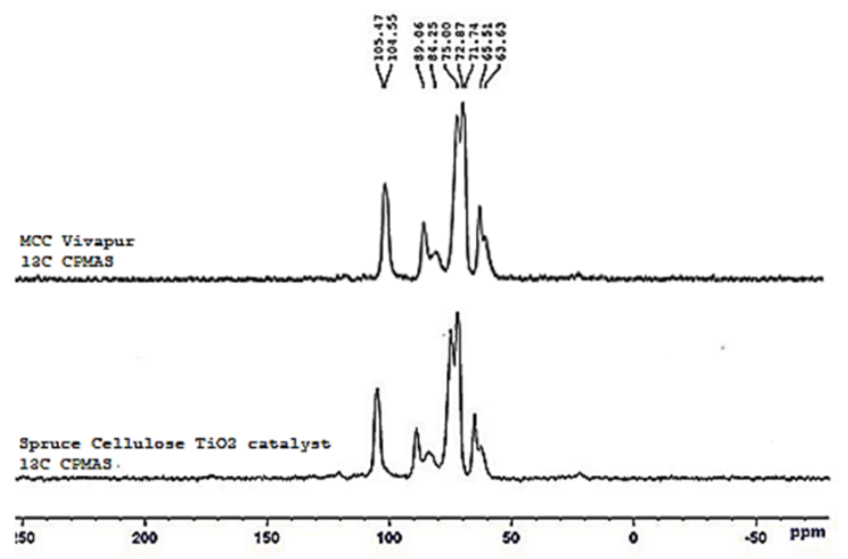

Fig.7 Solid state ${ }^{13} \mathrm{C}$ CP-MAS NMR spectra of cellulose
Table 4 Signal assignments for ${ }^{13} \mathrm{C}$ CP-MAS NMR spectrum of cellulose obtained by peroxide oxidation of spruce wood

\begin{tabular}{cc}
$\begin{array}{c}\text { Chemical } \\
\text { shift (ppm) }\end{array}$ & Assignment \\
\hline 105 & C-1 of cellulose \\
89 & C-4 of crystalline cellulose \\
84 & C-4 of amorphous cellulose \\
$72-75$ & C-2/C-3/C-5 of cellulose \\
65 & C- 6 of crystalline cellulose \\
62 & C-6 of amorphous cellulose
\end{tabular}

obtained from spruce wood and industrial MCC Vivapur

This high quality cellulose can be used for production of microcrystalline and nanocrystalline celluloses. Unique properties of microcrystalline cellulose (MCC) as nontoxicity, biodegradability, high mechanical strength are commonly used in medicine and the pharmaceutical, food, cosmetic and chemical industries [23]. MCC also can be used for the production of nanocrystalline cellulose, nanocomposites and functional polymers [24].

According to GC-MS data, the soluble products of spruce wood peroxide oxidation contain the mixture of organic acids: mono (acetic, formic, levulinic)-, dibasic (succinic, glutaric, fumaric, adipic) and hydroxyl acids (hydroxyacetic, 4-hydroxybenzoic), indicating deep oxidation of phenylpropane units of lignin at studied process conditions. Obviously the hydroxyl and peroxide radicals generated from $\mathrm{H}_{2} \mathrm{O}_{2}$ on the surface of $\mathrm{TiO}_{2}$ catalyst execute the oxidative destruction of aromatic rings in lignin. 


\subsection{Effect of wood nature on the features of wood biomass catalytic peroxide oxidation}

The main features of the process of peroxide oxidation of softwood (spruce, abies, pine, larch) and hardwood (aspen, birch) in acetic acid - water medium over $\mathrm{TiO}_{2}$ catalyst were compared (Fig.8 and Fig.9). It was found that the rise a temperature of peroxide oxidation, concentrations of $\mathrm{H}_{2} \mathrm{O}_{2}$ and $\mathrm{CH}_{3} \mathrm{COOH}$, a LWR decreases the content of lignin and hemicelluloses and increases the content of cellulose in the cellulose product, regardless of the wood nature.
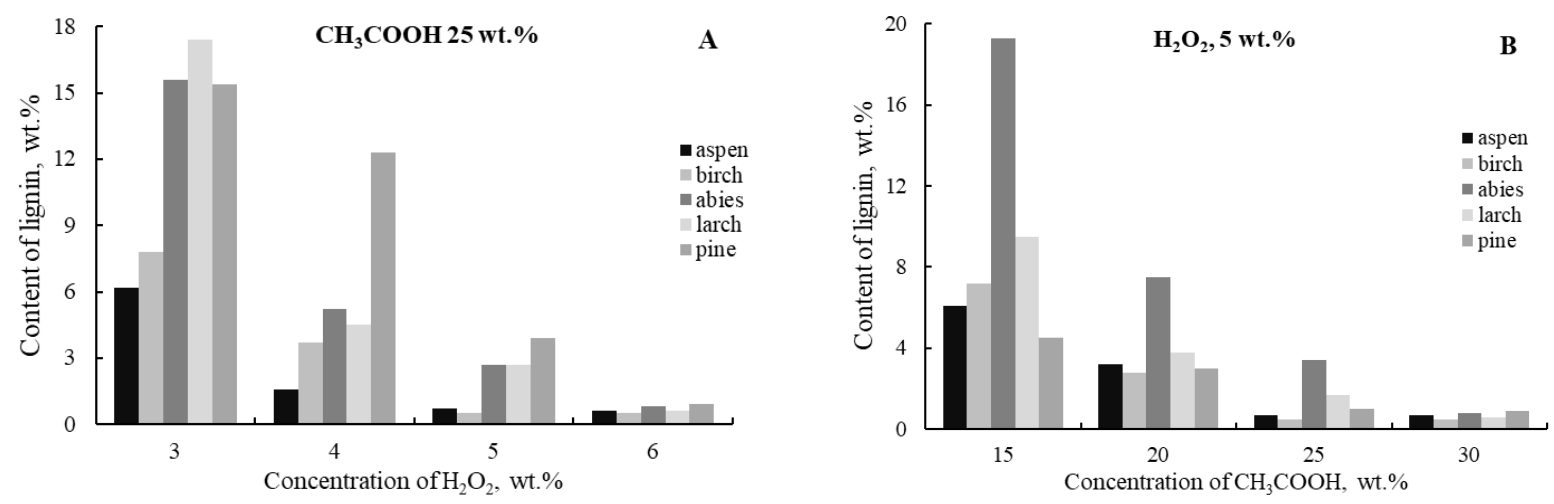

Fig.8 Influence of concentration of $\mathrm{H}_{2} \mathrm{O}_{2}(\mathrm{~A})$ and $\mathrm{CH}_{3} \mathrm{COOH}(\mathrm{B})$ on the content of lignin in cellulose products obtained by catalytic peroxide oxidation of hardwood and softwood in acetic acid - water medium over $\mathrm{TiO}_{2}$ catalyst $\left(100^{\circ} \mathrm{C}, \mathrm{LWR} 15\right.$, time $\left.4 \mathrm{~h}\right)$

The processes of catalytic peroxide oxidation of all wood species are described by the first order equations (Fig.9).
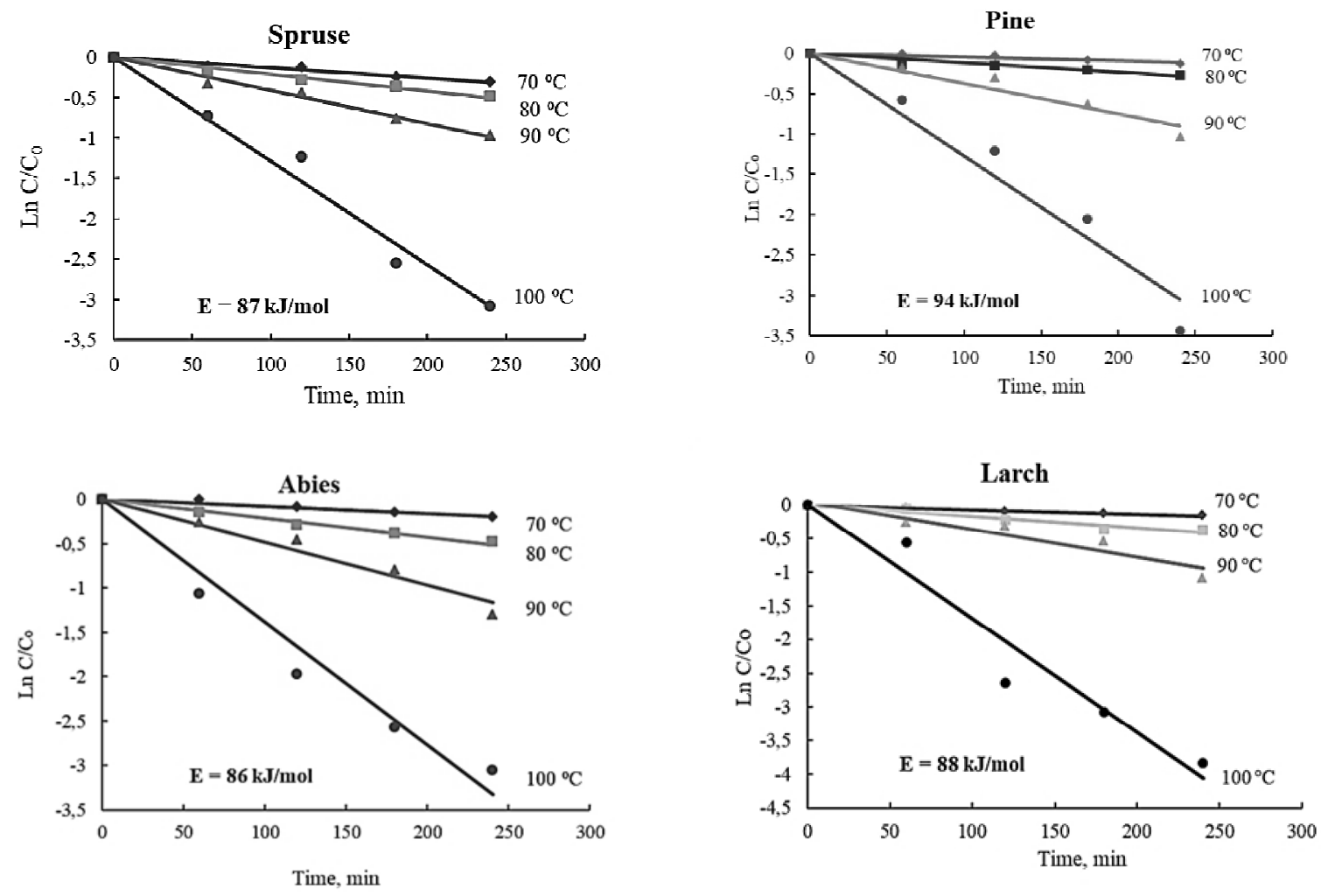

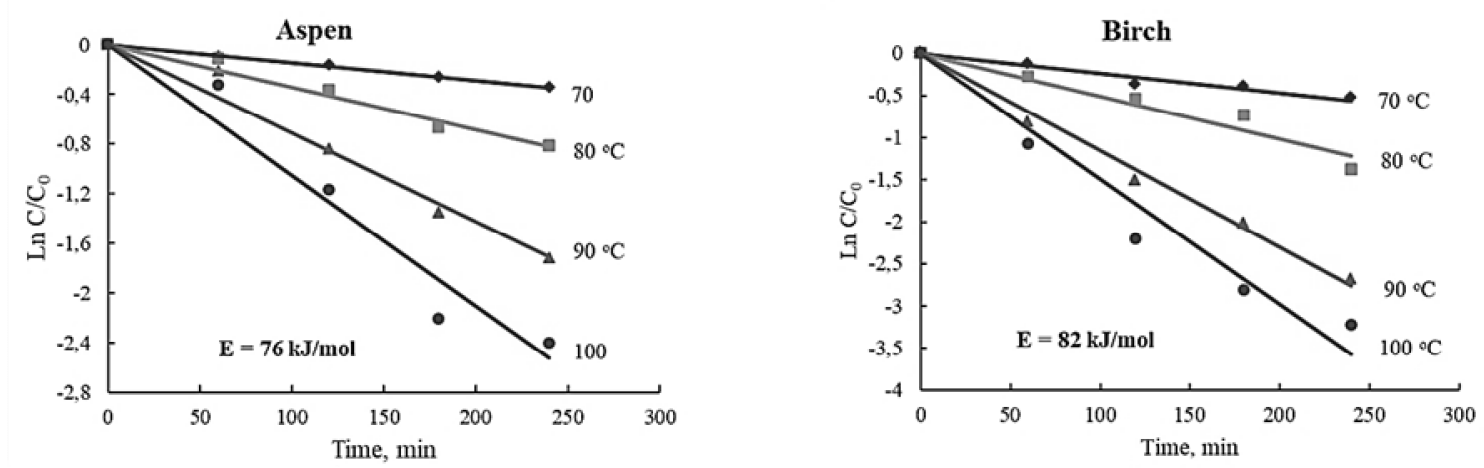

Fig.9 Dynamics of lignin removal in the processes of wood catalytic peroxide oxidation in acetic acid - water medium over $\mathrm{TiO}_{2}$ catalyst $\left(\mathrm{H}_{2} \mathrm{O}_{2} 5 \mathrm{wt} \%, \mathrm{CH}_{3} \mathrm{COOH} 25 \mathrm{wt} \%\right.$, LWR 15)

Activation energies of the processes of catalytic peroxide oxidation of softwood and hardwood species are varied between $76-94 \mathrm{~kJ} / \mathrm{mol}$ (Fig.9).

Softwood contains more lignin than hardwood; therefore the higher concentration of hydrogen peroxide is needed for deep oxidative delignification of spruce, pine, abies and larch wood compared with aspen and birch wood. At the temperature range $70-90{ }^{\circ} \mathrm{C}$ the peroxide delignification of hardwood proceeds with a higher rate as compared to softwood. Softwood lignins consisting of guaiacyl structural units are less reactive, than hardwood lignins, consisting predominantly of syringyl units alongside with guaiacyl units.

Cellulose products, obtained by peroxide oxidation of hardwood and softwood at optimal process condition have the structure of microcrystalline cellulose. Soluble products mainly consist of aromatic and aliphatic acids, mannose and glucose [25].

\subsection{Influence of the solvent nature on the features of abies wood peroxide oxidation over $\mathrm{TiO}_{2}$}

The main features of abies wood peroxide oxidation over $\mathrm{TiO}_{2}$ catalyst in the formic acid and acetic acid media were compared.

The process of abies wood peroxide oxidation in the formic acid medium proceeds with the formation of cellulose product and soluble lignin. But in the medium of acetic acid the cellulose product and organic acids are formed at the same conditions.

In both media the abies wood oxidation processes are described by the first order equations. The rate constants of wood oxidation in the medium of acetic acid are higher than that in the formic acid medium (Table $5)$.

Table 5 Rate constants and the activation energies of abies wood catalytic peroxide fractionation in $\mathrm{CH}_{3} \mathrm{COOH}$ and HCOOHmedia. $\left(\mathrm{H}_{2} \mathrm{O}_{2} 6 \mathrm{wt} \%\right.$; organic acid $30 \mathrm{wt} \%$; LWR 15)

\begin{tabular}{ccccc}
\hline \multirow{2}{*}{ Temperature, ${ }^{\circ} \mathrm{C}$} & \multicolumn{2}{c}{$\mathrm{CH}_{3} \mathrm{COOH}$} & $\mathrm{HCOOH}$ \\
\cline { 2 - 5 } & $\mathrm{k} \times 10^{-5}, \mathrm{~s}^{-1}$ & Activation energy, $\mathrm{kJ} / \mathrm{mol}$ & $\mathrm{k} \times 10^{-5}, \mathrm{~s}^{-1}$ & $\begin{array}{c}\text { Activation energy, } \\
\mathrm{kJ} / \mathrm{mol}\end{array}$ \\
\hline 70 & 0.8 & & 0.14 & \\
80 & 1.9 & 81 & 0.23 & 32 \\
90 & 4.9 & & 0.24 & \\
100 & 2.3 & & 0.32 & \\
\hline
\end{tabular}


But the activation energy of the process of wood oxidation in formic acid medium $(32 \mathrm{~kJ} / \mathrm{mol})$ is significantly lower as compared to acetic acid medium $(81 \mathrm{~kJ} / \mathrm{mol})$.

The rise of concentrations of $\mathrm{H}_{2} \mathrm{O}_{2}, \mathrm{HCOOH}, \mathrm{CH}_{3} \mathrm{COOH}$ and the value of liquid to wood ratio (LWR) increases the cellulose content in cellulose products and decreases the contents of hemicelluloses and lignin (Fig. 10). Simultaneously, the yield of the cellulose product decreases.

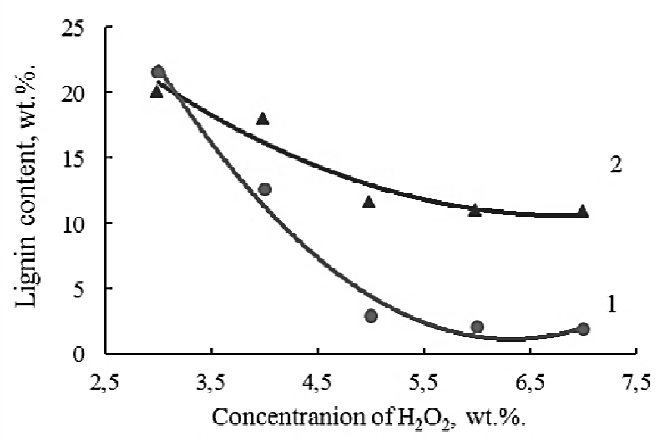

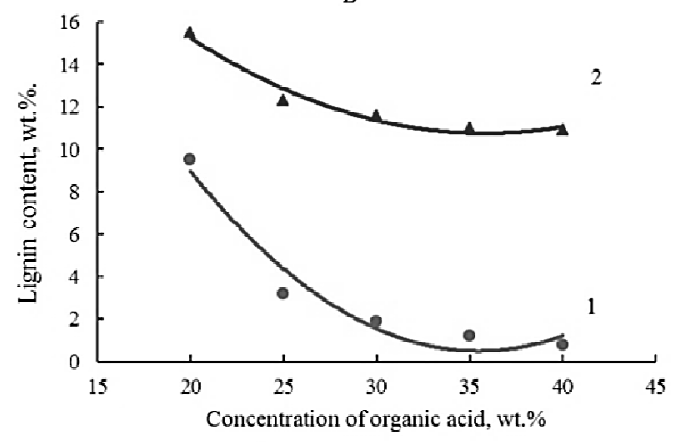

Fig.10 Influence of concentration of hydrogen peroxide (A) and organic acid (B) on the lignin content in the cellulose product: $1-\mathrm{CH}_{3} \mathrm{COOH} ; 2-\mathrm{HCOOH}\left(100{ }^{\circ} \mathrm{C}, \mathrm{H}_{2} \mathrm{O}_{2} 6 \mathrm{wt} \%\right.$, organic acid $30 \mathrm{wt} \%$, LWR $\left.15,4 \mathrm{~h}\right)$

When the acetic acid is used the higher degree of wood delignification is achieved compared to formic acid. At temperature $100{ }^{\circ} \mathrm{C} 93 \mathrm{wt} \%$ of lignin is removed from abies wood in the acetic acid medium. But only $61 \mathrm{wt} \%$ of lignin is removed at wood oxidation in formic acid medium.

In the presence of formic acid the hydrogen peroxide is consumed both in lignin depolymerization reactions and in reaction with $\mathrm{HCOOH}$ :

$$
\mathrm{HCOOH}+\mathrm{H}_{2} \mathrm{O}_{2} \longrightarrow \mathrm{CO}_{2}+2 \mathrm{H}_{2} \mathrm{O}
$$

The optimal composition of the reaction mixture differs for the processes of peroxide delignification of abies wood in the medium of formic and acetic acids. In order of achieve a high degree of wood delignification in the medium of "formic acid - water" it is necessary to use higher concentration of $\mathrm{H}_{2} \mathrm{O}_{2}(10 \mathrm{wt} \%)$ and of $\mathrm{HCOOH}(38 \mathrm{wt} \%)$ as compared to "acetic acid - water" medium (6 wt \% of $\mathrm{H}_{2} \mathrm{O}_{2}$ and $\left.30 \mathrm{wt} \% \mathrm{CH}_{3} \mathrm{COOH}\right)$.

This is due, on the one side, to a higher rate of $\mathrm{H}_{2} \mathrm{O}_{2}$ decomposition during peroxide delignification of wood in the presence of formic acid. This requires use the higher initial concentration of hydrogen peroxide. On the other side, in the processes of wood delignification in organic solvents the condensation reactions occur, especially in the presence of formic acid, whose acidity is an order of magnitude higher than acetic acid [26].

The acetylation reactions of primary and secondary aliphatic hydroxyls hinder lignin fragmentation by $\alpha$ - and $\beta-\mathrm{O}-4$ bonds. Therefore, during wood delignification in formic acid medium, the contribution of lignin fragmentation reactions reduce and the role of lignin solubilization increase significantly [27]. This requires the use in the process of wood delignification a higher concentration of formic acid (38 wt $\%)$ compared to acetic acid $(30 \mathrm{wt} \%)$.

In the process of abies wood peroxide delignification in the medium of "formic acid - water" the soluble lignin is formed. In contrast, in the medium "acetic acid - water", lignin undergoes a deep oxidative degradation with the formation of the mixture of organic mono -, dibasic and hydroxy acids [25]. 
At the optimal conditions of abies wood peroxide delignification in formic acid - water medium (100 ${ }^{\circ} \mathrm{C}, \mathrm{H}_{2} \mathrm{O}_{2}-10 \mathrm{wt} \%, \mathrm{HCOOH}-38 \mathrm{wt} \%$, LWR 15 , time $4 \mathrm{~h}$ ) two main products are formed: cellulose with yield of $94 \mathrm{wt} \%$ and lignin with yield of $21 \mathrm{wt} \%$ (with regard to their contents in the wood).

Elemental composition of lignin (wt \%): $\mathrm{C}-58.6 ; \mathrm{H}-4.7 ; \mathrm{O}-35.9$; atomic ratios $\mathrm{H} / \mathrm{C}-0.96 ; \mathrm{O} / \mathrm{C}-$ 0.46 , ash -0.74 .

In FTIR spectrum of lignin the absorption bands related to skeletal oscillations of the aromatic ring are present. The two most intensive absorption bands at $1269 \mathrm{~cm}^{-1}$ and at $1031 \mathrm{~cm}^{-1}$ indicate that this lignin belongs to the guaiacyl type which is characteristic of coniferous lignins. The presence of an intense band at $1724 \mathrm{~cm}^{-1}$ which corresponds to stretching vibrations of carbonyl groups indicates a high concentration of oxygencontaining groups in lignin.

According to GPC data, the lignin isolated by peroxide delignification of abies wood refers to low molecular weight lignin. Its number average molecular weight $\left(\mathrm{M}_{\mathrm{n}}\right)$ is $1127 \mathrm{~g} / \mathrm{mol}$ and weight average $\left(\mathrm{M}_{\mathrm{w}}\right)$ is $1854 \mathrm{~g} / \mathrm{mol}$. The degree of polydispersity equal to 1.65 indicates a sufficiently high homogeneity of lignin. This lignin is similar in molecular weight distribution to ethanol lignin [25].

The low molecular weight lignin, isolated by catalytic peroxide delignification of abies wood in the medium formic acid - water, has prospects to use for production of liquid hydrocarbons [7], enterosorbents [28], nanoporous carbon materials [29], aerogels [30] and functional polymers [31].

\subsection{Catalytic fractionation of wood by molecular oxygen}

The oxidation of wood by oxygen in water-alkaline medium proceeds with the formation of aromatic aldehydes and cellulose, according to the scheme:

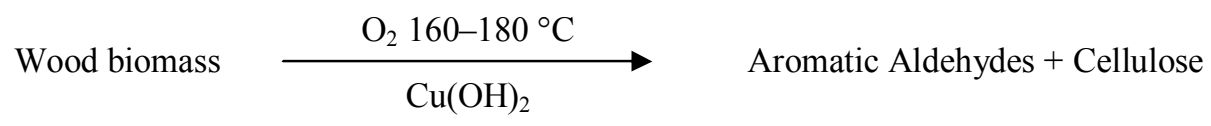

Softwood lignins constructed from phenylpropane units of guaiacyl type are oxidized to vanillin:

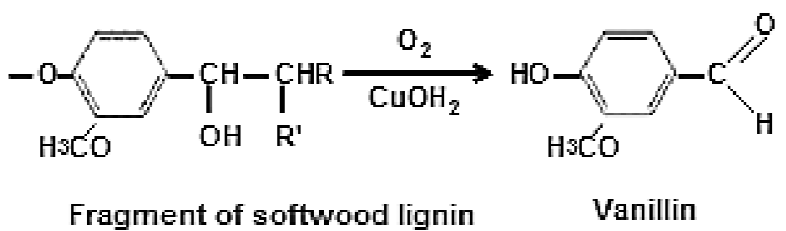

Hardwood lignins consist both from syringyl and guaiacyl units. The syringyl units are oxidized to syringaldehyde:

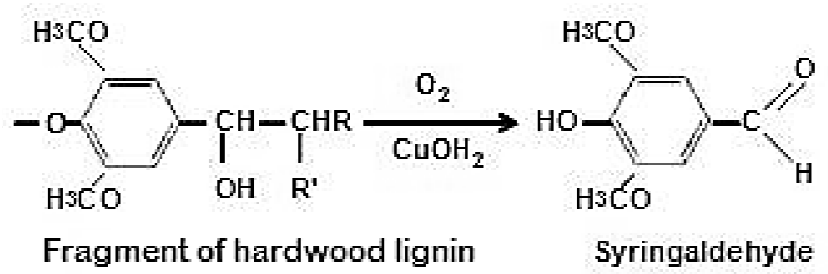


Some catalysts can increase by 1.5-2 times the yield of aromatic aldehydes at lignin oxidation by oxygen in water-alkaline medium [32].Transition metal oxide and hydroxides (Cu (II), Cu (III), Ag (I), Mn (IV) are used as catalysts for lignin oxidation to aromatic aldehydes. Among them the most active are copper catalysts. So, in the process of lignosulfonates oxidation the catalyst $\mathrm{Cu}(\mathrm{OH})_{2}(16 \mathrm{~g} / \mathrm{l})$ increases the yield of vanillin by 2 times compared to non-catalytic process. Catalyst $\mathrm{CuO}(4 \mathrm{~g} / \mathrm{l})$ increases the yield of vanillin from $12.9 \mathrm{wt} \%$ (non-catalytic process) to $23.1 \mathrm{wt} \%$ at pine wood oxidation by $\mathrm{O}_{2}$. The yield of aromatic aldehydes is higher in the catalytic oxidation of hardwood lignins compared to softwood lignins.

In order to optimize the process of birch wood oxidation by $\mathrm{O}_{2}$ in the presence of catalyst $\mathrm{Cu}(\mathrm{OH})_{2}$ the effect of temperature, liquid wood ratio (LWR) and time on the yield of aromatic aldehydes and cellulose was studied (Table 6, Fig. 11 and 12).

Table 6 Effect of temperature on the maximal yield of aromatic aldehydes in catalytic and non-catalytic oxidation of birch wood*

\begin{tabular}{ccccc}
\hline & \multicolumn{4}{c}{ Yield of aromatic aldehydes, wt $\%$ on lignin } \\
\hline Oxidation & \multicolumn{2}{c}{ Catalyst $\mathrm{Cu}(\mathrm{OH})_{2}$} & \multicolumn{2}{c}{ No catalyst } \\
\cline { 2 - 5 } temperature, ${ }^{\circ} \mathrm{C}$ & Vanillin & Syringaldehyde & Vanillin & Syringaldehyde \\
\hline 160 & 7.9 & 25.5 & - & - \\
170 & 13.0 & 30.2 & - & 8.1 \\
180 & 7.1 & 18.4 & 3.1 & 7.7 \\
190 & - & - & 3.0 & \\
\hline
\end{tabular}

* $60 \mathrm{ml}$ reaction mass, $3 \mathrm{~g}$ of wood, $11 \mathrm{~g} / \mathrm{l} \mathrm{Cu}(\mathrm{OH})_{2}, 10 \% \mathrm{NaOH}, 0,3 \mathrm{MPa} \mathrm{O}_{2}$, time $20 \mathrm{~min}$.

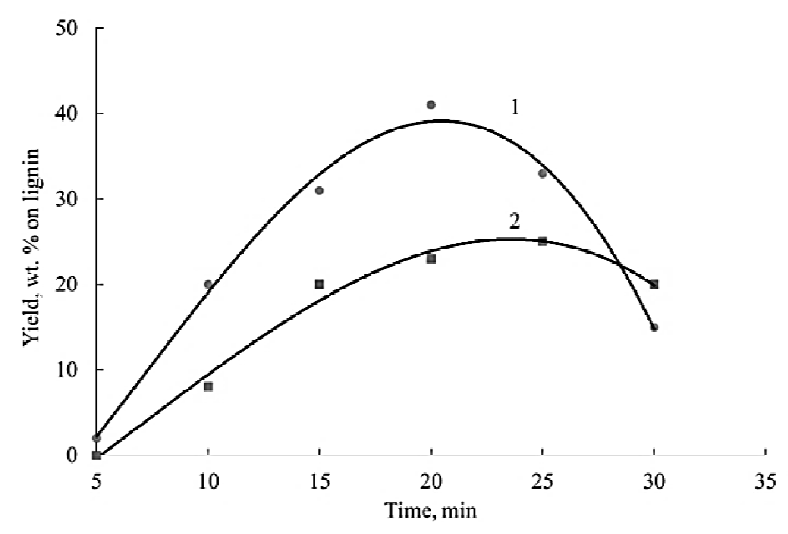

Fig.11 Dependence of the aromatic aldehydes yield on time of birch wood oxidation: $1-50 \mathrm{~g} / \mathrm{l}$ and $2-100 \mathrm{~g} / \mathrm{l}$ of sawdust. Process conditions: $170{ }^{\circ} \mathrm{C}, 11 \mathrm{~g} / \mathrm{l} \mathrm{Cu}(\mathrm{OH})_{2}$, oxygen pressure $-0,3 \mathrm{MPa}, 60 \mathrm{~g} / \mathrm{l} \mathrm{NaOH}$.

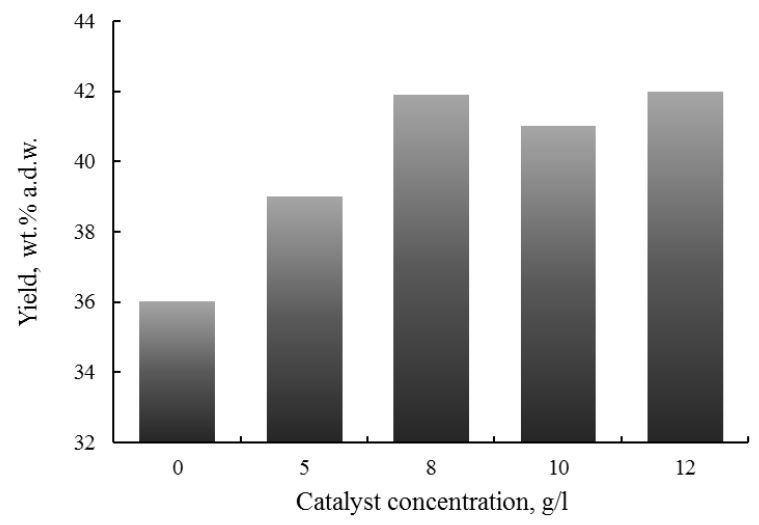


Fig.12 Yield of cellulose in the process of birch wood oxidation by oxygen in the presence of $\mathrm{Cu}(\mathrm{OH})_{2}$ catalyst at $170{ }^{\circ} \mathrm{C}$. Process conditions as in Table 5 .

In the temperature rage $160-190{ }^{\circ} \mathrm{C}$ the yield of vanillin and syringaldehyde goes through the maximum at oxidation temperature $170{ }^{\circ} \mathrm{C}$ (Table 7). The maximum yield of aromatic aldehydes at $170{ }^{\circ} \mathrm{C}$ reaches to $43 \mathrm{wt} \%$ relative to lignin in birch wood and the ratio vanillin: syringaldehyde is $1: 2.5$. The duration of reaching the maximum yield of aromatic aldehydes is reduced from 25 to 15 minutes with an increase in temperature of wood catalytic oxidation from 160 to $180{ }^{\circ} \mathrm{C}$.

As follows from the data obtained the increase of LWR raises the yield of aromatic aldehydes. The reduction of wood content in the reaction mixture from $100 \mathrm{~g} / 1$ to $50 \mathrm{~g} / 1$ increases both the yield of aromatic aldehydes and the initial rate of wood oxidation (Fig. 11). The observed reduction in aromatic aldehydes yield with increasing a wood content is due to diffusion restrictions at higher viscosity of the reaction medium.

The oxidation of wood by oxygen in water-alkaline medium allows to fractionate the wood biomass into aromatic aldehydes and cellulose. The yield of cellulose in the process of birch wood oxidation at $170{ }^{\circ} \mathrm{C}$ reaches to $36-42 \mathrm{wt} \%$ on a.d.w. (Fig. 12 ).

Birch wood differs from other wood species with a large concentration of hemicelluloses which requires a special approach to chemical processing of birch biomass. Preliminary hydrolysis of wood hemicelluloses allows to increase the range of products obtained from birch wood by processing of the resulting pentoses into furfural and xylitol.

In order to optimize the process of acid hydrolysis of birch wood hemicelluloses the influence of temperature, sulfuric acid concentration, LWR and time on the yield of pentoses was studied. From the data obtained it follows that the optimal conditions for obtaining hydrolysates predominantly containing pentoses (from 29 to $50 \mathrm{~g} / \mathrm{l}$ ) are the following: temperature $98{ }^{\circ} \mathrm{C}, \mathrm{H}_{2} \mathrm{SO}_{4}$ concentration $2-3 \%$, LWR 5.5-11, time 2-3 hours. The hemicelluloses-free birch wood was oxidized by $\mathrm{O}_{2}$ in water - alkaline medium in the presence of catalyst $\mathrm{Cu}(\mathrm{OH})_{2}$ to produce vanillin and syringaldehyde. Data on the yield of vanillin and syringaldehyde from preliminary hydrolyzed birch wood are presented in Table 7.

Table 7 Yield of aromatic aldehydes from preliminary hydrolyzed birch wood*

\begin{tabular}{cccc}
\hline $\begin{array}{c}\text { Concentration of } \\
\mathrm{H}_{2} \mathrm{SO}_{4}, \mathrm{wt} \%\end{array}$ & $\begin{array}{c}\text { Hydrolysis } \\
\text { temperature, }{ }^{\circ} \mathrm{C}\end{array}$ & Vanillin & Yield, wt $\%$ on lignin \\
\cline { 3 - 4 } 2 & 98 & 4.5 & Syringaldehyde \\
3 & 98 & 5.5 & 14.5 \\
5 & 98 & 3.8 & 17.7 \\
32 & 60 & 5.2 & 12.6 \\
\hline
\end{tabular}

* temperature of hydrolyzed wood oxidation $170{ }^{\circ} \mathrm{C}$, LWR 10 , time $20 \mathrm{~min}$.

Based on these data the optimal conditions for the integrated processing of birch wood into pentoses, vanillin, syringaldehyde and cellulose were established. Hydrolysis of birch wood by $3 \% \mathrm{H}_{2} \mathrm{SO}_{4}$ at temperature $98{ }^{\circ} \mathrm{C}$ during 3 hours allows to produce $25-28 \mathrm{wt} \%$ of pentoses that can be processed into furfural and xylitol. Catalytic oxidation of hydrolyzed wood by $\mathrm{O}_{2}$ at $170{ }^{\circ} \mathrm{C}$ during $20 \mathrm{~min}$ produces $4.4 \mathrm{wt} \%$ of vanillin and syringaldehyde and 40-43 wt\% of cellulose product. Cellulose product obtained from hydrolyzed birch wood contains no hemicelluloses. The acidic hydrolysis of this cellulose product allows to produce the levulinic acid, according to the scheme: 


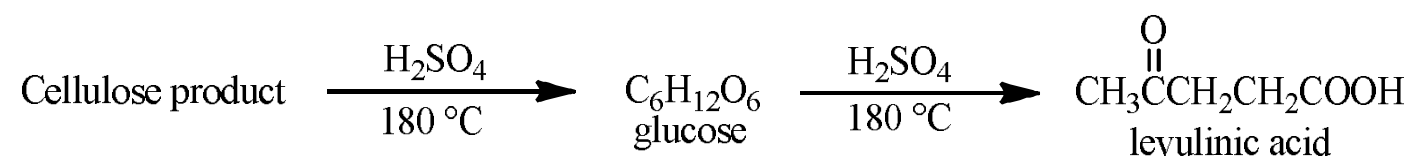

At optimal process conditions the yield of levulinic acid from cellulose product reaches to $32 \mathrm{wt} \%$ (Table 8).

Table 8 Levulinic acid (LA) yield at acid-catalyzed conversion of cellulose product obtained in the process of birch wood catalytic oxidation*

\begin{tabular}{lllllll}
\hline Process duration, h & 1.0 & 2.0 & 2.5 & 3.0 & 3.5 & 4.0 \\
Yield of LA, wt\% & 9.3 & 23.5 & 31.6 & 32.7 & 30.9 & 25.4 \\
$\begin{array}{l}\text { Concentration of LA in reaction } \\
\text { medium, g/l }\end{array}$ & 11.6 & 29.4 & 39.5 & 40.9 & 38.6 & 31.7 \\
$\begin{array}{l}\text { Yield of humic residue, wt\% } \\
\text { y } \%\end{array}$ & - & - & 23.8 & 20.2 & 18.5 & 28.3 \\
\hline
\end{tabular}

* temperature $180{ }^{\circ} \mathrm{C}, 2 \% \mathrm{H}_{2} \mathrm{SO}_{4}, \mathrm{LWR} 8$

The final yield of levulinic acid is $22-25 \%$ on mass of cellulose product and $10-11 \%$ on mass of initial birch wood, taking into account the losses at the separation and purification stages. Integration of the considered catalytic processes of oxidative and acidic conversions of biomass components makes it possible to offer the scheme of complex processing of birch wood to a range of valuable chemical products (Fig. 13).

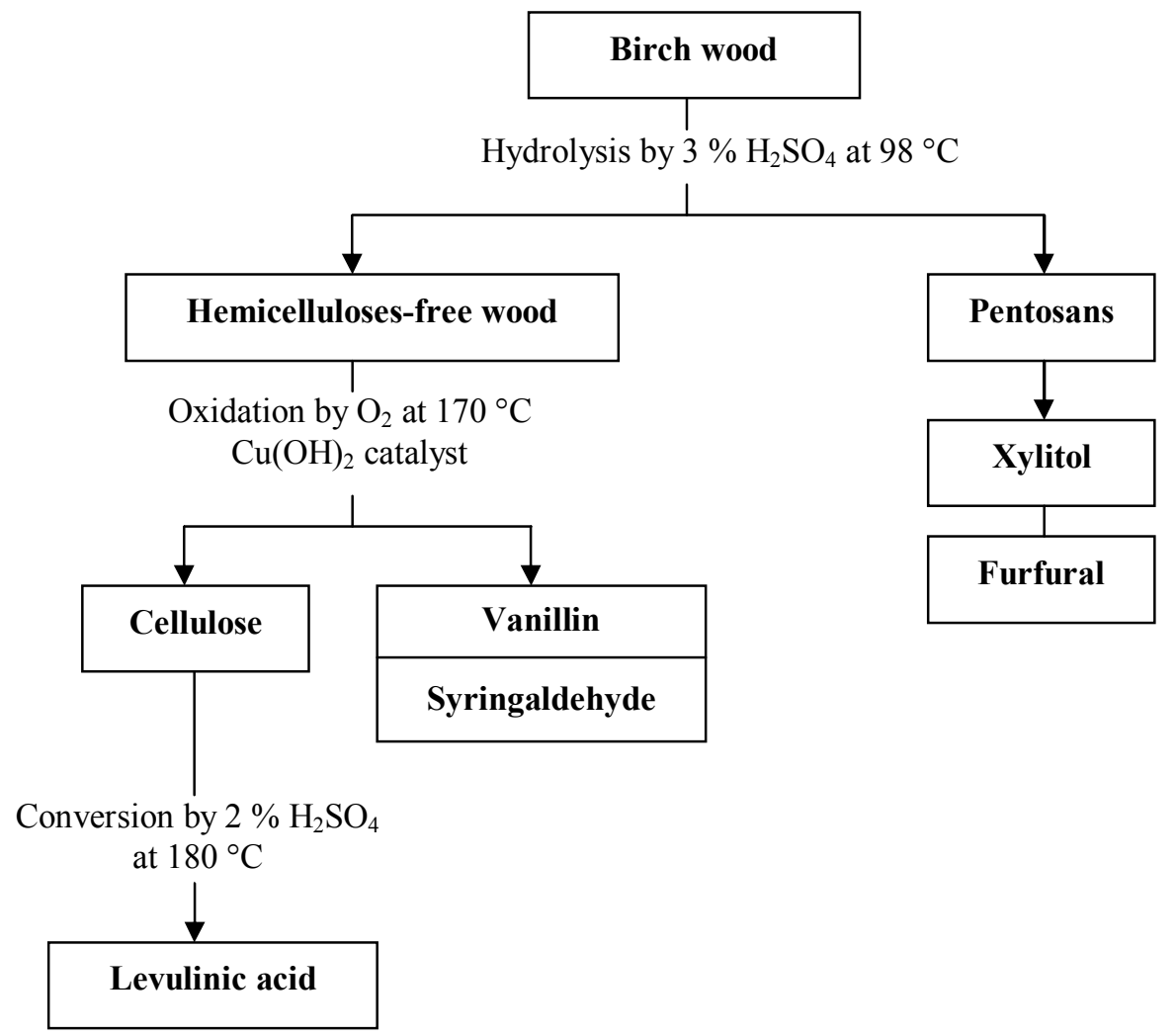

Fig.13 Scheme of complex processing of birch wood biomass to valuable products 
The developed scheme includes a stage of acid hydrolysis of woody hemicelluloses to pentoses which can be processed into furfural and xylitol according to known technologies [33]. Catalytic oxidation of hemicelluloses-free wood produces vanillin, syringaldehyde and cellulose. Acid-catalyzed conversion of cellulose produces levulinic acid.

Vanillin and syringaldehyde are used in pharmaceutical, food, and fragrance industries [34]. Syringaldehyde can also be transformed into substituted anthraquinones - the catalysts of alkaline delignification [35]. A possibility of production of new polymers from vanillin may be mentioned [36]. Levulinic acid is applied for obtaining of valuable chemicals and biodegradable polymer production [37].

The advantage of the developed scheme is the possibility of complex processing of the main components of birch wood biomass into a set of valuable chemical products with the use of green delignification reagent - molecular oxygen.

\section{Conclusion}

Firstly the kinetic study of spruce wood peroxide oxidation in the medium of "acetic acid-water" over suspended catalyst $\mathrm{TiO}_{2}$ was accomplished. The process of wood oxidative delignification is described by the first order equation at the temperature range $70-100{ }^{\circ} \mathrm{C}$. At these temperatures the rate constants of spruce wood oxidative delignification are varied between $0.22 \cdot 10^{-4} \mathrm{~s}^{-1}$ and $2.15 \cdot 10^{-4} \mathrm{~s}^{-1}$. The rather high activation energy (87 $\mathrm{kJ} / \mathrm{mol}$ ) points on the minor contribution of external diffusion limitations at the used conditions of wood peroxide delignification.

By experimental and numerical optimization the conditions of spruce wood peroxide delignification providing a high yield $(47.8 \mathrm{wt} \%)$ of quality cellulose with residual lignin content $1.3 \mathrm{wt} \%$ were established: temperature $100{ }^{\circ} \mathrm{C}$, concentration of $\mathrm{H}_{2} \mathrm{O}_{2} 6 \mathrm{wt} \%, \mathrm{CH}_{3} \mathrm{COOH} 25 \mathrm{wt} \%$, LWR 15, duration $4 \mathrm{~h}$. According to FTIR, XRD, ${ }^{13} \mathrm{C}$ CP-MAS NMR and SEM data, the cellulose obtained by spruce wood catalytic oxidation has the structure of microcrystalline cellulose.

The effect of wood species and organic solvent nature on the features of wood peroxide oxidation over $\mathrm{TiO}_{2}$ catalyst was investigated. The kinetic regularities of the processes of softwood (spruce, abies, pine, larch) and hardwood (aspen, birch) catalytic oxidation in "acetic acid-water" medium are similar. But the higher concentrations of $\mathrm{H}_{2} \mathrm{O}_{2}$ and $\mathrm{CH}_{3} \mathrm{COOH}$ are needed for deep oxidative delignification of softwood compared to hardwood.

The nature of organic solvent influences significantly on the process of catalytic peroxide oxidation of wood. The process of abies wood peroxide oxidation over $\mathrm{TiO}_{2}$ catalyst proceeds in the formic acid medium with the formation of cellulose and soluble lignin. But in the medium of acetic acid the cellulose and organic acids are formed at the same process conditions.

Solid products of wood peroxide oxidation were characterized by FTIR, XRD, SEM, solid state ${ }^{13} \mathrm{C}$ CP-MAS NMR and soluble products were identified by GC-MS.

The influence of conditions of birch wood oxidation by oxygen in "water-alkaline" medium in the presence of suspended catalyst $\mathrm{Cu}(\mathrm{OH})_{2}$ to aromatic aldehydes and cellulose was investigated. At temperature range $160-180^{\circ} \mathrm{C}$ the yield of aromatic aldehydes goes through a maximum at oxidation temperature $170{ }^{\circ} \mathrm{C}$ and reaches to $43 \mathrm{wt} \%$ relative to lignin in birch wood (ratio vanillin: syringaldehyde is $1: 2.5$ ). 
The scheme of biorefinery of birch wood, based on catalytic fractionation of wood biomass by oxygen with production of pentoses, vanillin, syringaldehyde and levulinic acid was developed. The resulting products are in demand in many areas, including food, pharmaceutical, chemical and cosmetic industries, synthesis of new functional polymers. Levulinic acid is considered as a renewable compound for producing various chemicals and biodegradable polymers.

Acknowledements The reported study was supported by Russian Science Foundation, Grant No. 16-13-10326.

\section{Referances}

1. Jing Y, Guo Y, Xia Q, Liu X, Wang Y (2019) Catalytic production of value-added chemicals and liquid fuels from lignocellulosic biomass. Chem 5:1-27

2. Yung MM (2016) Catalytic conversion of biomass to fuels and chemicals. Top Catal 59:1

3. Rowell RM (2012) Handbook of wood chemistry and wood composites. 2nd edn. CRC Press

4. Sixta H (2006) Handbook of pulp. Wiley-VCH Verlag GmbH \& Co, Weinheim

5. Besson M, Gallezot P, Pinel C (2014) Conversion of biomass into chemicals over metal catalysts. Chem Rev 114(3):1827-1870

6. Serrano-Ruiz JC, Dumesic JA (2011) Catalytic routes for the conversion of biomass into liquid hydrocarbon transportation fuels. Energy Environ Sci 4:83-99

7. Zakzeski J, Bruijnincx PCA, Jongerius AL, Weckhuysen BM (2010) The catalytic valorization of lignin for the production of renewable chemicals. Chemical Reviews 110 (6):3552-3599

8. Cherubini F, Jungmeier G, Wellisch M, Willke T, Skiadas I, Ree RV, Jong Ed (2009) Toward a common classification approach for biorefinery systems. Biofuels, Bioproducts and Biorefining 3 (5):534-546

9. de Long E, Hidson, A, Walsh P (2013) Task 42. Biorefinery In: Report IEA Bioenergy

10. Anderson EM, Katahira R, Reed M, Resch MG, Karp EM, Beckham GT, Roman-Leshkov Yu (2016) Reductive catalytic fractionation of corn stover lignin. ACS Sustain Chem Eng 4:6940-6950

11. Van den Bosch S, Schutyser W, Vanholme R, Drissen T, Koelewijn SF, Renders T, De Meester B, Huijgen WJJ, Dehaen W, Courtin CM, Lagrain B, Boerjan W, Sels BF (2015) Reductive lignocellulose fractionation into soluble lignin-derived phenolic monomers and dimers and processable carbohydrate pulps. Energy Environ Sci 8:1748-1763

12. Tarabanko VE, Kaygorodov KL, Skiba EA, Tarabanko NV, Chelbina YV, Baybakova OV, Kuznetsov BN, Djakovitch L, Pinel C (2017) Processing pine wood into vanillin and glucose by sequential catalytic oxidation and enzymatic hydrolysis. J Wood Chem Technol 37:43-5113

13. Suchy M, Argyropoulos D (2001) Catalysis and activation of oxygen and peroxide delignification of chemical pulps: a review. ACS Symp Ser 785:2-43

14. SongYo Wi SG, Kim HM, Bae HJ (2016) Cellulosic bioethanol production from Jerusalem artichoke (Helianthus tuberosus L.) using hydrogen peroxide-acetic acid (HPAC) pretreatment. Bioresour Technol 214:30-36

15. Dussan K, Girisuta B, Haverty D, Leahy JJ, Hayes MH (2014) The effect of hydrogen peroxide concentration and solid loading on the fractionation of biomass in formic acid. Carbohydr Polym 111:374384 
16. Kuznetsov BN, Chesnokov NV, Yatsenkova OV, Sharypov VI, Garyntseva NV, Ivanchenko NM, Yakovlev VA (2017) Green catalytic valorization of hardwood biomass into valuable chemicals with the use of solid catalysts. Wood Science and Technology 51 (5):1189-1208

17. Kuznetsov BN, Sudakova IG, Garyntseva NV, Levdansky VA, Ivanchenko NM, Pestunov AV, Djakovitch L, Pinel C (2018) Green biorefinery of larch wood biomass to obtain the bioactive compounds, functional polymers and nanoporous materials. Wood Science and Technology 52 (5):1377-1394

18. Analytical Methods in Wood Chemistry, Pulping and Papermaking (1999). Springer Series in Wood Science. Springer-Verlag Berlin Heidelberg

19. Hu F, Jang S, Ragauskas A (2012) Pseudo-lignin formation and its impact on enzymatic hydrolysis. Bioresour Technol 117:7-12

20. Park S, Baker JO, Himmel ME, Parilla PA, Jonson DK (2010) Cellulose crystallinity index: measurement techniques and their impact on interpreting cellulose performance. Biotechnol Biofuels 3:10

21. Wikberg H, Maunu SL (2004) Characterization of thermally modified hard- and softwoods by ${ }^{13} \mathrm{C}$ CPMAS NMR. Carbohydr Polym 58:461-466

22. Zuckerstätter G, Schild G, Wollboldt P, Röder T, Weber HK, Sixta H (2009) The elucidation of cellulose supra molecular structure by 13C CP-MAS NMR. Lenzing Ber 87:38-46

23. Trache D, Hussin MH, Chuin CTH, Sabar S, Fazita MRN, Taiwo OFA, Hassan TM, Haafiz MKM (2016) Microcrystalline cellulose: Isolation, characterization and bio-composites application - A review. International Journal of Biological Macromolecules 93: 789-804

24. Mishra S, Kharkar PS, Pethe AM (2019) Biomass and waste materials as potential sources of nanocrystalline cellulose: Comparative review of preparation methods (2016 - Till date). Carbohydrate Polymers 207: 418427

25.. Kuznetsov BN, Chesnokov NV, Sudakova IG, Garyntseva NV, Kuznetsova SA, Malyar YuN, Yakovlev VA, Djakovitch L (2018) Green catalytic processing of native and organosolv lignins. Catalysis Today 309:18-30

26. Germer EI (2003) Chemistry of delignification under organosolv cooking. Lesnoy Zhurnal-Forestry Journal 4: 99-108

27. Ede RM, Brunow G (1989) Reactions of $\beta$-aryl ether lignin model compounds under formic acid and peroxyformic acid pulping conditions. The Intern.Symp.on Wood and Pulping Chemistry. Raleigh, NC, USA

28. Garyntseva NV, Sudakova IG, Kuznetsov BN (2011) Properties of enterosorbents obtained from acetic acid lignins of abies, aspen and birch wood. Journal of Siberian Federal University. Chemistry 4(2): 121-126

29. Ivanov IP, Mikova NM, Lutoshkin MA, Chesnokov NV, Kuznetsov BN (2017) The study of structure and properties of nanoporous carbon materials obtained by alkaline thermal activation of lignin of fir wood. Journal of Siberian Federal University. Chemistry 10(3): 390-400

30. Grishechko LI, Amaral-LabatG, SzczurekA, Fierro V, Kuznetsov BN, Pizzi A, Celzard A (2013) New tannin-lignin aerogels. Industrial Crops and Products 41:347-355

31. Kuznetsov BN, Vasilyeva NYu, Kazachenko AS, Skvortsova GP, Levdansky VA, Lutoshkin MA (2018) Development of the method of abies wood ethanol lignin sulfonation using sulfamic acid. Journal of Siberian Federal University. Chemistry 11(1): 122-130 
32. Tarabanko VE, Tarabanko NV (2017) Catalytic oxidation of lignins into the aromatic aldehydes: general process trends and development prospects. Int. J. of Molecular Sciences 18: 2421-2449

33. Brazdausks P, Puke M, Vedernikovs N, Kruma I (2013) Influence of biomass pretreatment process time on furfural extraction from birch wood. Environmental and climate technologies 11: 478-485

34. Mashkovsky, MD (2014) Medicinal Products. Novaya Volna: Moskow, Russia

35. Heitner C; Dimmel DR, Schmidt JA (eds) (2010) Lignin and Lignans: Advances in Chemistry; CRC Press: London, UK; New York, NY, USA

36. Zhou J, Zhang H, Deng J, Wu Y (2016) High glass-transition temperature acrylate polymers derived from biomasses, syringaldehyde, and vanillin. Macromol.Chem. Phys. 217: 2402-2408

37. Gallezot P (2012) Conversion of biomass to selected chemical products. Chemical Society Reviews 41: 1538-1558 